\title{
Risk Factors for Conjunctival Microorganism Colonization in Adults Undergoing Intraocular Surgery*
}

\author{
Orly Halachmi-Eyal $^{1 \#}$, Yoram Keness ${ }^{2}$, Yaron Lang ${ }^{1}$, Daniel Briscoe ${ }^{1,3}$, Dan Miron ${ }^{3,4}$ \\ ${ }^{1}$ Department of Ophthalmology, Afula, Israel; ${ }^{2}$ Clinical Microbiology Laboratory, Afula, Israel; ${ }^{3}$ Ruth and Bruce Rappaport School \\ of Medicine, Haifa, Israel; ${ }^{4}$ Pediatric Infectious Disease Consultation Service, Ha'Emek Medical Center, Afula, Israel. \\ Email: \#orly.halachmi@gmail.com
}

Received January $16^{\text {th }}, 2012$; revised February $18^{\text {th }}, 2012$; accepted March $14^{\text {th }}, 2012$

\begin{abstract}
Purpose: To assess prevalence of and risk factors for conjunctival colonization and types of organisms among adults undergoing elective intraocular surgery. Setting: Ha'Emek Medical Center, Afula, Israel. Methods: A prospective study conducted in the Ophthalmology Department at Ha'Emek Medical Center, Afula, Israel between May 1, 2006 and August 31, 2007. Included were adults undergoing elective intraocular surgeries. Conjunctival cultures were obtained from the lower fornix, prior to application of prophylactic decolonization treatment and were processed using routine microbiological techniques. Demographic, socioeconomic and medical data of our patient cohort were obtained from all participants. Results: Cultures were obtained from 501 patients. (Mean age $69.7 \pm 12.0$ years) of whom $52.1 \%$ were females. In 208 patients (40.5\%) bacteria grew in conjunctival cultures, one type in 175 (34.9\%) one, and two types in 28 (5.6\%). In none fungi were isolated. Coagulase negative Staphylococcus was the most frequent bacteria isolated. By multivariate analysis, significant risk factors for conjunctival bacterial colonization were spring/summer seasons (OR: 1.64, CI: $1.15-2.36, \mathrm{P}<0.007$ ), and showering on the day of the operation (OR: 1.73 , CI: $1.11-2.69, \mathrm{P}<0.01)$. Conclusions: In addition to previously known risk factors for conjunctival microorganism colonization, the present study found showering on the morning of the operation, possibly related to bacteria on towels or in the eyelids and lashes, and time of year (spring/summer) perhaps resulting from higher temperature and humidity related to the presence of conjunctival bacteria to be significant in adults undergoing intraocular surgery.
\end{abstract}

Keywords: Conjunctiva; Culture; Bacteria; Coagulase Negative Staphylococcus; Cataract; Shower; Climate

\section{Introduction}

The pathogenesis of post-operative endophthalmitis (POE) is associated in most parts with penetration of microorganisms (mostly bacteria) from the conjunctiva into the eye ball during the ocular surgical procedure. The most common pathogens associated with in POE are coagulase negative staphylococcus (CNS) (70\%), Staphylococcus areus (24\%), gram negative rods (6\%), Propionibacterium acnes, Pseudomonas aeroginosa, and Hamophilus influenza [1].

Data regarding colonization of microorganisms in the conjunctival sac prior to ocular surgery are scarce. In a previous paper we published our conjunctival culture results in comparing prospectively two methods of preoperative prophylaxis [2]. The aim of the present study was to identify risk factors and to assess their prevalence

\footnotetext{
*Synopsis: The present study found showering on the morning of the operation, and warm season to be significantly related to bacteria yield in conjunctiva cultures in adults undergoing intraocular surgery.

${ }^{\#}$ Corresponding author.
}

in reference to conjunctival colonization as well as to determine types of organisms found among adult patients undergoing elective intraocular surgery.

There is a known correlation between conjunctival bacterial detection and co-existence of an ocular surface disease, (i.e. blepharitis and conjunctivitis). Chronic immunocompromised disease conditions and indiscriminate use of antibiotics and corticosteroids are associated with fungal growth. Hot climate was also shown to be associated with increased prevalence of bacterial recovery from the conjunctiva [3].

\section{Materials and Methods}

The current study was conducted between May 1st 2006 and August 31st 2007 in the Ophthalmology Department at Ha'Emek Medical Center, Afula, Israel. The study was approved by the local Internal Review Board and written informed consent was obtained from each patient prior to recruitment.

Included were patients $>18$ years old attending an 
elective intra-ocular surgery. Patients undergoing emergency treatment, with pre-existing primary or secondary immune-compromised conditions, those being treated with local or systemic antibiotic or steroidal agents, debilitated patients, or those suffering from inter-current local or systemic infectious disease were excluded. Patients with chronic renal failure treated with dialysis were also excluded. Demographic and socioeconomic data included gender, age, place of residence (urban/rural), work place (indoor/outdoor), level of formal education, the season of the operation day and showering on the morning of the operation. Medical data were obtained including drug and drops intake, presence of hypertension, anemia, diabetes, heart, kidney, hormonal, pulmonary and mental diseases as well as the season, and showering on the morning of the operating day.

\subsection{Workup}

Conjunctival baseline cultures were obtained approximately two hours before the operation (prior to the application of any prophylactic therapy). We obtained two smears from the lower conjunctival fornix of each patient by using Copan transwab applicators in an Amies transport medium that was seeded on a chocolate agar at bedside. Specimens were processed according to routine microbiological methods [4]. Transwab specimens were further seeded on selective and enriched agar cultures for aerobe bacteria and fungi and were incubated for 48 - 72 hours before microorganism colonization was recorded. Routine microbiology methods were used for identification of the microorganisms isolated and determination of their susceptibility patterns [4].
Patients were generally treated with diclofenac sodium $1 \mathrm{mg} / \mathrm{ml}$ (Voltaren ${ }^{\circledR}$ Ophtha, Novartis, Switzerland) one drop instilled 3 times/day for three days prior to the surgery, in such a way that the last drop was applied on the evening before the operation.

\subsection{Statistical Analysis}

The prevalence of particular bacteria was computed per 1000 cultures. $\mathrm{X}^{2}$ tests were used to assess the risk of categorical data. Ordinal regression analysis with a logit link was used to obtain an estimate of the common odds ratio for the significant variables. Test of parallel lines was performed.

\section{Results}

Five hundred and one subjects were included in the study of whom $261(52.1 \%)$ were female. The mean age was $69.7 \pm 12.0$ (range 18 - 92). Overall, 233 bacteria were isolated in $203(40.5 \%)$ patients' conjunctival sacs. In 175 patients, one or more $(34.9 \%)$ bacterial isolates were retrieved. In $28(5.6 \%)$ subjects two bacterial isolates were retrieved. No cultures showed isolated fungi. The most prevalent bacteria was CNS, isolated in 170 (33.9\%) patients (Table 1).

Significant factors for growth of at least one type of organism in culture analyzed by univariate and stepwise regression multivariate analysis are shown in Table 2. Showering on the morning of the operation and spring/ ummer seasons were both significant risk factors for retrieving one or more bacteria in culture. No other variables were statistically significant factors associated with

Table 1. Microorganisms isolated in the conjunctival sac in 501 patients.

\begin{tabular}{|c|c|c|c|}
\hline Bacteria & Overall N (\%*) & As a sole isolate $\mathrm{N}(\%)$ & As a mixed isolate $\mathrm{N}(\%)$ \\
\hline CNS & $170(33.9)$ & $145(28.9)$ & $25(5.0)$ \\
\hline Streptococcus viridans & $14(2.8)$ & $0(0)$ & $14(2.8)$ \\
\hline Staphylococcus areus (methicillin sensitive) & $10(2.0)$ & $9(1.8)$ & $1(0.2)$ \\
\hline Corynebacterium sp. & $8(2.0)$ & $6(1.2)$ & $2(0.4)$ \\
\hline Proteus mirabilis & $6(1.2)$ & $4(0.8)$ & $2(0.4)$ \\
\hline Bacillus sp. & $5(1.0)$ & $3(0.6)$ & $2(0.4)$ \\
\hline Hemophilus sp. & $4(0.8)$ & $2(0.4)$ & $2(0.4)$ \\
\hline Citrobacter diversus & $4(0.8)$ & $1(0.2)$ & $3(0.6)$ \\
\hline Staphylococcus areus (methicillin resistant) & $3(0.6)$ & $2(0.4)$ & $1(0.2)$ \\
\hline Others** & $9(1.8)$ & $5(1.0)$ & $4(0.8)$ \\
\hline Overall & 233 & 177 & 56 \\
\hline
\end{tabular}

*Percent of all patients; **Diphteroids, Streptococcus pneumonia, Acinetobacter sp.-2 isolates each, Morganella morganii, Pseudomonas sp., and Enterobacter brevis - 1 isolate each. 
Table 2. Univariate and multivariate analysis for variables associates with any bacterial growth in conjunctival culture.

\begin{tabular}{|c|c|c|c|c|c|}
\hline \multirow{2}{*}{ Variable (N value) } & \multirow{2}{*}{$\begin{array}{l}\text { Any bacterial } \\
\text { growth N (\%) }\end{array}$} & \multicolumn{2}{|c|}{ Univariate analysis } & \multicolumn{2}{|c|}{$\begin{array}{c}\text { Multivariate analysis } \\
\text { for independent variables }\end{array}$} \\
\hline & & OR (95\% CI) & $\mathbf{P}$ & OR (95\% CI) & $\mathbf{P}$ \\
\hline $\begin{array}{c}\text { Showering on the morning of o } \\
\text { No (124) } \\
\text { Yes }(335)\end{array}$ & $\begin{array}{c}37(29.8) \\
142(42.4)\end{array}$ & $1.73(1.11-2.69)$ & $=0.01$ & $1.62(1.03-2.54)$ & $=0.03$ \\
\hline $\begin{array}{c}\text { Season } \\
\text { Autumn-Winter (254) } \\
\text { Spring-Summer (247) }\end{array}$ & $\begin{array}{c}88(34.6) \\
115(46.6)\end{array}$ & $1.64(1.15-2.36)$ & $=0.007$ & $1.50(1.03-2.20)$ & $=0.03$ \\
\hline $\begin{array}{l}\text { Hypertension } \\
\text { Yes (183) } \\
\text { No (328) }\end{array}$ & $\begin{array}{l}117(36.8) \\
86(47.0)\end{array}$ & $0.66(0.45-0.95)$ & $=0.03$ & $0.67(0.47-1.03)$ & $=0.07$ \\
\hline
\end{tabular}

bacterial yield in cultures. History of hypertension was associated with lower rate of conjunctival bacterial colonization by univariate analysis, only.

By univariate analysis significant risk factors for mixed growth of bacteria in cultures were warm season (OR: 1.66, 95\% CI: $1.17-2.37, \mathrm{P}<0.02$ ), showering on the morning of the operation (OR: $1.72,95 \% \mathrm{CI}: 1.11$ 2.66, $\mathrm{P}<0.05$ ), and hypertension (OR: 0.64, $\mathrm{P}<0.03$ ). Educational level tended to be a risk factor $(\mathrm{P}<0.08)$. Multivariate analysis using season, showering, blood pressure and education level revealed that showering (OR: 1.72, 95\% CI: $1.11-2.66, \mathrm{P}<0.03$ ), warm season (OR: 1.53, 95\% CI: $1.04-2.24, \mathrm{P}<0.03$ ) and no formal education (OR: $1.62,95 \% \mathrm{CI}: 1.01-2.60, \mathrm{P}<0.05$ ) were significant risk factors for mixed growth of bacteria while hypertension was not (OR: 0.71, 95\% CI: 0.48 1.05, $\mathrm{P}<0.09)$.

\section{Discussion}

We previously published our results of conjunctival cultures taken from healthy adults prior an elective intraocular surgery [2]. Bacteria were isolated from 40.5\% of the conjunctiva of adults, of which CNS was the most prevalent occurring in $33.9 \%$ cases. In that prospective double-blind controlled study we compared the effecttiveness of adding preventive treatment of Moxifloxacin $0.5 \%$ ophthalmic drops on Povidone-Iodine 5.0\% solution alone for disinfection of the conjunctiva prior surgery. We found that the addition of Moxifloxacin 0.5\% drops on the conventional treatment with Povidone-Iodine $5.0 \%$ prior the surgery, had no significant effect on further reduction in the bacterial colonization rate from the conjunctiva. In the current study, we looked at the risk factors related to the presence of bacteria in conjunctival cultures and we found showering on the morning of the operation and spring/summer seasons were both significant risk factors for conjunctival colonization.

In Table 3, results of similar studies that examined the rate and the bacterial type in conjunctival cultures are presented. As seen in the table, positive cultures were found to be between $20 \%$ and $80 \%$; CNS was quite abundant in the conjunctiva and derived from $30 \%-80 \%$ of normal cultures. This is in accordance with the results of the Endophthalmitis Vitrectomy Study (EVS) [2] where CNS was by far the most abundant bacteria in culture positive post-operative endophthalmitis (POE), occurring in $70 \%$ of cases.

Other prevalent bacteria are Corynebacterium sp., Staphylococcus Aureus and Streptococcus viridance. Corynebacterium $s p$. was scarcer in our study compared to its prevalence in the literature [5], where it accounts for up to $30 \%-40 \%$ of the microorganisms in culture. Being a facultative anaerobe, this may be related to the use of aerobic bacteria agar, and will be discussed later.

Risk factors for conjunctival growth: Previously known risk factors for retrieving bacteria from the conjunctiva include: advanced age, local risk factors (chronic use of topical medications, contact lens wear, blepharitis, chronic eyelid or conjunctival inflammation) and systemic risk factors (immunosuppression, diabetes, skin disorders, asthma, autoimmune conditions and those taking immunosuppressant medications) [6].

According to our findings, the time of year (spring/ summer) is a significant independent risk factor for conjunctival colonization. Higher temperature and humidity were shown to be related to the presence of conjunctival bacteria [7]. Of 4432 patients studied in Madrid, Spain, prevalent bacteria were CNS (>60\%); Corynebacterium sp. (>33\%), Staphylococcus aureus $(>8 \%)$, and other Gram-positive bacteria ( $>2.5 \%)$ and other Streptococcus sp. $(>6 \%)$. Also, in this study, the incidence of rehospitalisation for endophthalmitis after cataract extraction in warm months (May and June together) was 3.37 times higher than in the other months. In another study, hot climate was shown to be associated with the presence of certain bacteria in the conjunctiva especially Staphyloccocus Epidermidis in India [8].

Showering in the morning of the operation is also a significant risk factor in our study. While this conclusion 
Table 3. Studies assessing prevalence of bacterial growth in conjunctival culture obtained from adults (*CNS - Coagulase negative staphylococcus).

\begin{tabular}{|c|c|c|c|c|}
\hline Reference & $\mathbf{N}$ & Overall positive cultures $\mathbf{N}(\%)$ & CNS* N (\%) & Other-relatively frequent $(>10 \%) \mathrm{N}(\%)$ \\
\hline Yang et al. [9] & 133 & $61(45.8)$ & $25(41)$ & $\begin{array}{l}\text { Staphlococcus aureus } 23(37.7) \\
\text { Gram-positive rods } 13(21.3)\end{array}$ \\
\hline Leong et al. $[10]$ & 98 & $64(65)$ & $35(55)$ & Corynebacterium 40 (63) \\
\hline Fernández et al. [11] & 4432 & $3461.4(78.1)$ & $2521(56.9)$ & $\begin{array}{c}\text { Gram positive bacteria } 3236(93.5) \\
\text { Corynebacterium sp. } 1055(30.5)\end{array}$ \\
\hline Herde et al. [12] & 686 & $126(18.4)$ & $109(86.5)$ & \\
\hline Current study & 501 & $233(46.5)$ & $170(73)$ & \\
\hline Overall & 5850 & & & \\
\hline
\end{tabular}

may seem unlikely, we assume that the reasons are related to bacteria that exist on towels or in the eyelids and lashes (e.g. in chronic blepharitis), which can potentially expose them to a large inoculum when rubbing their eyelids. Another reason might be related to lowering the normal peri-ocular inoculum, enabling exposure to pathogenic bacteria, but we could not found literature that supported these parameters. A further study might be required, specifically focusing on the technique of washing and drying the eyes.

\section{Limitations of the Study}

In our study, we excluded potential risk factors such as chronic immune-compromised disease conditions and indiscriminate use of antibiotics and steroids. We did have difficulties in standardizing local risk factors such as the presence of blepharitis or other ocular surface disorders because of the large number of participants (both patients and medical staff). Furthermore, because of technical issues, only aerobic bacteria were analyzed at the laboratory. The rationale for that was that aerobic bacteria cause more than $94 \%$ of all POE cases [1] while obligate anaerobes have a negligible role in endophthalmitis. According to the EVS, Propionibacteria acnes and Propionibacteria granulosum were the only obligatory anaerobic bacteria isolated in the POE cases and constituted just $0.6 \%$ of all the 323 confirmed growth isolates. Furthermore, since both microorganisms need a laboratory incubation period of more than 6 days, it was impractical to culture every conjunctival specimen of the more than 500 specimens for this extended period of time under anaerobic conditions in order to retrieve a mere $<1 \%(0.6 \%)$ of the microorganisms.

\section{Acknowledgements}

The authors did not receive any financial support from any public or private sources.

The authors have no financial or proprietary interest in a product, method, or material described herein.

\section{REFERENCES}

[1] D. P. Han, S. R. Wisniewski, L. A. Wilson, et al., "Spectrum and Susceptibilities of Microbiologic Isolates in the Endophthalmitis Vitrectomy Study," American Journal of Ophthalmology, Vol. 122, No. 1, 1996, pp. 1- 17.

[2] O. E. Halachmi, Y. Lang, Y. Keness and D. Miron, "Preoperative Topical Moxifloxacin $0.5 \%$ and Povidone-Iodine $5.0 \%$ versus Povidone-Iodine 5.0\% Alone to Reduce Bacterial Colonization in the coNjunctival Sac," Journal of Cataract Refractive Surgery, Vol. 35, No. 12, 2009, pp. 2109-2114. doi:10.1016/j.jers.2009.06.038

[3] M. G. Speaker and J. A. Menikoff, "Prophylaxis of Endophthalmitis with Topical Povidone-Iodine," Ophthalmology, Vol. 98, No. 12, 1991, pp. 1769-1775.

[4] K. Todar, "The Bacterial Flora of Humans," Online Textbook of Bacteriology, University of Wisconsin-Madison, Madison, 2002.

[5] U. Bachrach, J. Gurevitch, J. Landau and D. Birnbaum, "The Flora of the Normal Conjunctiva of Healthy People in Israel," Acta Medica Orientalia, Vol. 12, No. 1, 1953, pp. 3-10.

[6] H. M. De Kaspar, C. N. Ta, et al., "Prospective Study of Risk Factors for Conjunctival Bacterial Contamination in Patients Undergoing Intraocular Surgery," European Journal of Ophthalmology, Vol. 19, No. 5, 2009, pp. 717-722.

[7] E. F. Rubio, "Climatic Influence on Conjunctival Bacteria of Patients Undergoing Cataract Surgery," Eye (Lond), Vol. 18, No. 8, 2004, pp. 778-784. http://www.textbookofbacteriology.net. doi: $10.1038 /$ sj.eye. 6701352

[8] V. P. S. Tomar, O. P. Sharma and K. Joshi, "Bacterial and Fungal Flora of Normal Conjunctiva," Annals of Ophthalmology, Vol. 6, 1971, pp. 669-671.

[9] W. Yang, L. Kuang, F. Deng, et al., "Study on Bacterial Strains in Conjunctival Sac before and after Intraocular Surgery," Eye Science, Vol. 15, No. 4, 1999, pp. 267-269.

[10] J. k. Leong, R. Shah, P. J. Mc Clusskey, et al., "Bacterial Contamination of the Anterior Chamber during Phacoemulsification Cataract Surgery," Journal of Cataract and Refractive Surgery, Vol. 28, No. 5, 2002, pp. 826-833.

[11] R. E. Fernández, "Conjunctival Bacteria of Patients Undergoing Cataract Surgery: Changes in the Last 50 Years," 
Archivos de la Sociedad Española de Oftalmología, Vol. 79, No. 1, 2004, pp. 13-19.

[12] J. Herde, M. Tost, D. Wilhelms, et al., "Perioperative
Conjunctival Flora," Klinische Monatsblätter für Augenheilkunde, Vol. 209, No. 7, 1996, pp. 13-20.

doi:10.1055/s-2008-1035270 